\title{
La Validez Predictora del Examen para el Certificado de Secundaria en el Estado de Osun (Nigeria)
}

\author{
B.A. Faleye y E.R.I. Afolabi
}

Dept of Educational Foundations and Counselling,

Facultad de Educacion,

Universidad Obafemi Awolowo, Ile-Ife

Nigeria

delewolu@yahoo.com.au 


\section{Resumen}

Introducción: El Junior Secondary Certificate Examination (JSCE, examen estandarizado) es un examen acumulativo que hacen los candidatos al final (tercer curso) del primer ciclo de educación secundaria (Junior Secondary Education) en Nígeria El examen tiene dos versiones: (a) la que realizan las delegaciones de educación de los estados (State Ministries of Education, MOE), y (b) la versión Federal que realiza el Consejo Nacional de Exámenes (National Examinations Council, NECO). Había preocupación creciente entre los implicados sobre la validez predictora de la versión estatal de la JSCE con respecto al Senior Secondary Certificate Examination (SSCE, examen paralelo administrado al final del segundo y último ciclo de educación secundaria). Se realizó este estudio para averiguar si hay relación significativa entre el rendimiento global de los estudiantes en el JSCE y su rendimiento en el Senior School Certificate Examination (SSCE).

Método: Los institutos del estado de Osun (de Nigeria) constituyeron la muestra para este estudio. A través de procedimientos de análisis correlacional, se compararon las puntuaciones de los estudiantes en sus exámenes finales del primer curso del segundo ciclo (Senior Secondary School, SSS 1), del segundo curso (SSS 2), y sus puntuaciones en el SSCE en seis asignaturas principales con sus puntuaciones correspondientes del JSCE.

Resultados: Se demostró que el $J S C E$ del estado de Osun no predice el rendimiento de los estudiantes en el SSCE. Sin embargo, se encontró que la Lengua y las Matemáticas del JSCE tenían mayor capacidad para predecir el rendimiento en Lengua y Matemáticas del SSCE, en contraste con las demás asignaturas $(\mathrm{r}=0.32, \mathrm{p}<0.05$ y $\mathrm{r}=0.22 \mathrm{p}<0.05$ respectivamente $)$.

Conclusión: Rendimiento global en el JSCE para las seis asignaturas investigadas es mal

predictor del rendimiento en el SSCE (con la excepción de Lengua y Matemáticas). Esta tendencia puede deberse a las limitaciones a las que se enfrentan las delegaciones (MOE) que desempeñan el papel de un organismo de exámenes.

Keywords: JSCE; SSCE; Validez predictora, rendimiento, Nigeria 